\title{
Adaptive Learning Mode of a Multimedia-based "English Literature" Learning System
}

\author{
https://doi.org/10.3991/ijet.v12i01.6483 \\ Jie Mei \\ Hebei North University, Hebei, China \\ meijiehbnu@163.com \\ Yanhong Guo \\ Hebei North University, Hebei, China \\ Xiaokun Li \\ Hebei North University, Hebei, China
}

\begin{abstract}
In this paper, a multimedia-based English pronunciation learning system was designed. On this basis, a self-adaptive learning mode which consists of the teaching mode and the independent learning mode was proposed. The self-adaptive teaching model uses corpus technology and covers the exploratory "3I" (Illustration-Interaction-Induction) teaching model, thereby changing the traditional teaching pattern of "spoon-feeding"; when it comes to the independent learning mode, the self-adaptive system can automatically set corresponding learning tasks according to the learning situation of students, to improve the autonomy and differences of students' self-learning. At the same time, the approach of comparative teaching was especially adopted to test the validity of this system and the learning mode. Specifically, the exquisite course of "English Literature" for students of Grade 2015 majoring in English was selected as the experimental group, to compare with the learning situation of their counterparts of Grade 2014 in the last year. The results show that the learning mode is remarkable in its teaching practicality, could bring a significant effect on improving teaching efficiency and students' independent learning ability, and enjoys a high research value and a promising application prospect.
\end{abstract}

Keywords-Multimedia English teaching, corpus, self-adaptive learning, teaching application

\section{Introduction}

With the development of information technology, multimedia technology has been widely applied to various fields since its rise in the 1990s [1]. Gradually, multimediaaided teaching, especially multimedia-aided foreign language teaching, has received 
extensive attention. Multimedia teaching can comprehensively process texts, images, audios, videos, etc. Usually, it refers to a teaching program or software designed through comprehensive utilization of a variety of multimedia technology in accordance with the teaching objective, teaching object and teaching content, to achieve processing, transmission, demonstration and feedback of the teaching content [2]. At present, multimedia foreign language teaching, because of its rich representation ability, high interactivity and multi-faceted demonstration, has basically realized overall coverage in the field of language education. These advantages are more conducive to stimulate students' interest in learning and improve their competence of independent learning [3]. Since the 20th century, in addition to routine teaching, the education department overseas has carried out a series of multimedia teaching and research for the two centers of technology and educators in a number of ways, such as comparative study on multimedia and traditional teaching, intervening in learning of different learners, and using multimedia as a tool of cognition and interaction. In China, multimedia foreign language teaching has been widely concerned by national policy and people from all walks of life. Noticeably, multimedia hardware construction and software resource construction cover almost all schools [4].

$\mathrm{Xu}$ Bin and Zhuang Yi applied the self-adaptive learning theory to medical multimedia teaching. Their experimental results show that students would select the mutation strategies on the basis of implementation of a self-adaptive learning framework through learning from their previous performances in developing effective solutions. The validity of SALIA was verified by 26 state-of-the-art optimization problems with different characteristics like noise, mis-scale, ill-condition, rotation, multi-modality and uni-modality [5]. Babaee et al. believed that the use of ICT for the development of learning skills can stimulate the acquisition of new competences and extend basic information channels. Students gain more knowledge and retain it better when IT-assisted learning is used in a cooperative environment. As indicated in the experience of developing and using multimedia products, the application of these products in the foreign language teaching process can achieve a sound teaching effect [6]. In foreign language teaching, Tian Liang and Du Xiaobing constructed an APP technology platform, combined it with students' smart phones, thereby provided inspiration for the application of multimedia foreign language teaching, and found a certain prospect in face of the teaching method [7].

However, there are still many shortcomings in the field of multimedia foreign language teaching, especially in China: 1) some surveys found that the majority of English teachers and even college English teachers use multimedia teaching only in the form of PPT and CD-ROM provided with textbooks. Consequently, the foreign language class has actually become a demonstration of courseware. Nevertheless, this form gives merely the electronic display of knowledge on textbooks, resulting in the loss of interaction between teachers and students in the traditional teaching pattern and the failure to realize the original intention of multimedia teaching [6]; 2) the lack of innovation and high-quality teaching courseware is another problem. For English learning, oral and listening exercises play a significant role. Nonetheless, a survey revealed that $37 \%$ of teaching courseware is just the direct electronic transfer of 
teaching materials, or even copy or "spoon-feeding" teaching, paying less attention to the cultivation of students' competence in speaking and listening. Therefore, such teaching courseware does not play the true role of multimedia application [8]; 3) currently, most multimedia teaching is still in the stage of non-targeted teaching, meaning that it cannot target at different students in accordance with their different basic ability and learning ability; 4) presently, students are engaged in foreign language teaching in a passive manner due to their shortage of initiative [9].

Aiming to solve the problems of multimedia foreign language teaching mentioned above, this study designed a multimedia pronunciation learning system, and proposed an adaptive learning mode based on this system. This learning mode overcomes the aforementioned problems in multimedia foreign language teaching: 1) each student can clearly see the content of teaching via a distributed computer, and the teacher can interact with students at any time, to correct their pronunciation whenever necessary and to improve the quality and efficiency of teaching; 2) due to the use of corpus technology, the learning mode can provide targeted learning for each student according to their different mastery situation, learning materials and difficulty; 3 ) students' learning could be transformed from the traditional pattern of passive acceptance to active acquisition. Students are allowed to control their own learning pace, strategy and difficulty, so as to improve their learning autonomy and innovation; 4) provided with a variety of learning models, students can choose their own learning model in line with their own preference, to improve their learning efficiency.

\section{Framework of the Self-adaptive Learning Mode}

Speaking in English, listening training is the key to teaching foreign language learning, and the current use of multimedia teaching mostly loudspeakers, projectors and other equipment, the effect is far from good speaker and headset broadcasting effect, and projector screens for students different angle, distance and other factors will directly affect the visual effects.

\subsection{Self-adaptive Learning Theory}

The purpose of adaptive learning theory is to achieve real-time personalized education. Self-adaptive learning has been defined as "a learning system that provides learning support for individual characteristics in response to differences in individual learning processes" [10]. Other researchers have put forward the definition of selfadaptive learning from the three levels of study, including "connectivity, content and culture" [11]. The emphasis of this paper is that the system constructed based on selfadaptive learning theory can provide learners with individualized learning services. The implementing channel of this system lies in the comprehensive analysis of learners' learning style, cognitive level and other background factors, thus to provide corresponding personalized services. Self-adaptive learning, mostly data-oriented, is a concrete method to realize individualized learning among learners. It analyzes learners' ability level according to real-time data collected, so as to recommend the 
most suitable learning materials (such as the English pronunciation audio and video in this study, English reading articles, etc.) and strategies for the time being.

The framework of this design is shown in Figure 1. It mainly includes two modes, namely, the corpus-based teaching mode (see detailed description in the teachercontrolled teaching mode framework, and the corpus-based independent learning mode (see detailed description in the student-controlled independent learning mode framework. The establishment and formation of corpus is the basic resource in the theoretical and applied research of linguistics. Through using corpus-based English teaching applications, teachers can select appropriate teaching tasks, set teaching objectives, engage in classroom teaching and offer timely supervision and guidance. Meanwhile, students can provide feedbacks of their learning and lectures to teachers through the independent learning mode, and participate in classroom communication or interaction to improve teaching quality.

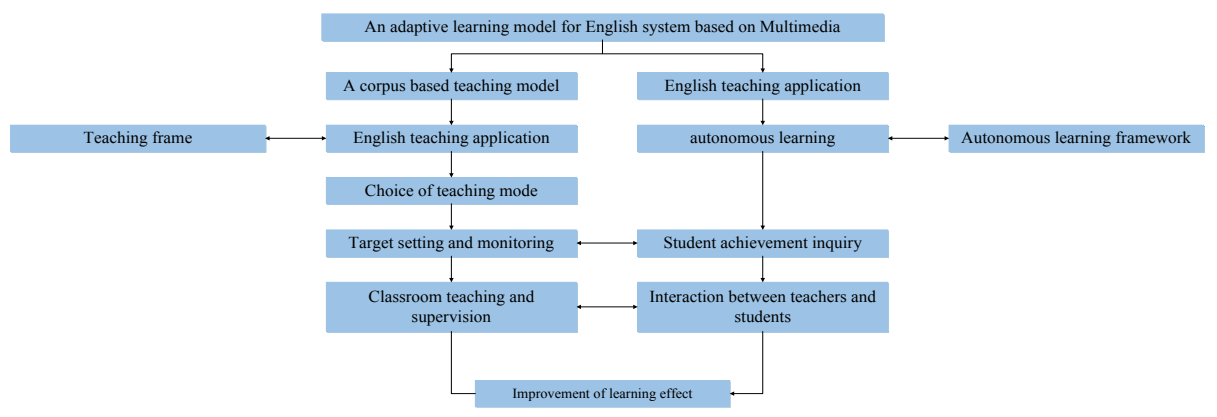

Fig. 1. Framework of the self-adaptive learning mode of the multimedia-based pronunciation system

\subsection{Design of the multimedia English pronunciation learning system}

English speaking and listening training is a key link of foreign language acquisition. However, most multimedia teaching currently is carried out by the use of loudspeakers, projectors and other equipment which are lagging far behind headsets in terms of the sound effect. Furthermore, projectors directly affect the visual effect among students because of light, angle and other problems. The designed set of multimedia English pronunciation teaching system can perfectly overcome these problems.

As shown in Figure 2, the multimedia English pronunciation study system mainly includes 1 . Teaching function of the learning system: it is compatible with the analog language lab function, covering overall calls, individual calls, demonstration and other traditional functions; at the same time, the equipped electronic whiteboard can transfer the content entered by the teacher to students in the form of textual explanation and achieve live recording of interactive teaching in the form of audio files which are available for on-demand review. 2. Auxiliary Learning System: it supports English audio or broadcasting listening, such as listening to the British BBC 
radio. 3. Cycled review system: the scene of teaching by the teacher can be played through the playing software to in memory loop, and basically maintains the original English speaking rate and tone. 4: Learning supervision system: the function of student sign-in can make a roll call. The software can display students' corresponding name, and provide quizzes or examinations of which the results can be used as usual scores for feedback on learning effect. 5: Learning mode for free choice: One is the corpus-based teaching mode (see details in the teacher-controlled teaching mode framework), while the other is the corpus-based independent learning mode (see details in the student-controlled independent learning mode framework).

The student display especially configured in this learning system can be utilized for display; the recording device record answers by each student and compare their pronunciation with the standard pronunciation, to identify pronunciation problems and improve students' speaking and listening ability. The scanner on the teachercontrolled desk can scan printed documents, transfer them to each student through the master controller and master control distributor, and demonstrate them on the display.

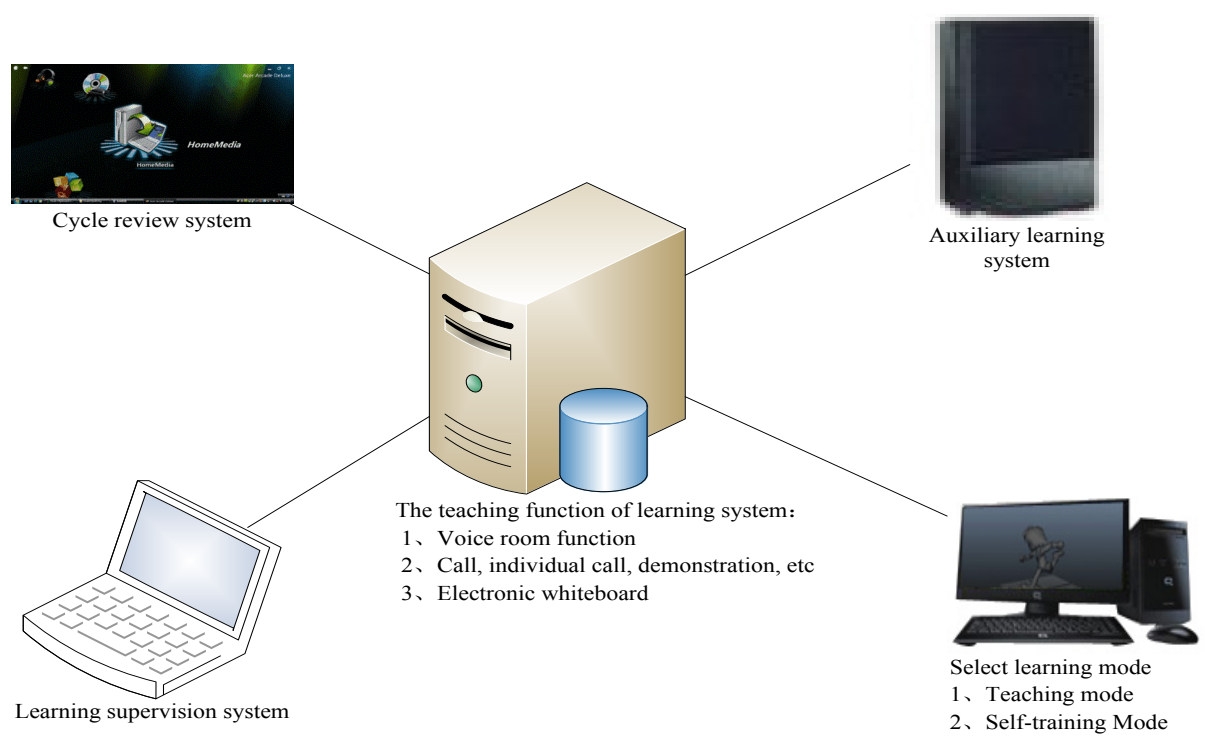

Fig. 2. Structure of the Multimedia English Pronunciation Learning System

\subsection{Design of corpus}

Corpus refers to a large-scale electronic text library built after scientific sampling and processing. With the help of computer analysis tools, researchers can carry out relevant researches on language theory and application [12]. At present, corpus has been widely used in the field of teaching, resulting in the development momentum of mutual integration and mutual promotion between language teaching and corpus research. The application of corpus in teaching can be divided into direct application, 
indirect application and teaching-oriented corpus design. Currently, there is no mature teaching-oriented corpus in China. This study was mainly concerned with the direct application of corpus and the design of teaching-oriented corpus (i.e., corpus-based teaching mode and corpus-based independent learning mode), while the indirect application of corpus mainly means the publication of reference books, for which no specific description is given here.

The corpus-based teaching mode, as shown in Figure 3, refers to the use of corpus by teachers in the teaching process. Compared with the traditional teaching mode, the corpus-based teaching mode is the data-driven teaching mode which uses the exploratory 3I (Illustration-Interaction-Induction) model. Illustration means guiding students to observe the real corpus; interaction enables students to exchange, discuss and share their acquisitions of in the process of observing the corpus; induction implies that students induce and summarize corresponding rules of knowledge points for the observed corpus. These practices are based on observation, discussion and induction of a large number of corpuses. This teaching method has changed the traditional "spoonfeeding" teaching method, engages students in research and summarization, and encourages them to explore in learning and learn in exploring.

The teacher-controlled teaching mode framework consists of the following five steps and involves two databases:

1. Setting the teaching content and goal. Teachers set the teaching content according to the teaching progress, students' learning situation and the database of teaching materials.

2. Selecting the teaching material in accordance with the teaching content. On the basis of the analysis in step 1, the appropriate teaching material is chosen from the database of teaching corpus.

3. Setting the training mode. The corresponding training mode is set through the database of teaching materials and the database of teaching corpus according to the teaching material and teaching content.

4. Classroom teaching. Teaching tasks in the training mode are completed.

5. Teaching evaluation and feedback. Teaching evaluation is conducted for the teaching content; the evaluation results will be fed back to the database of teaching materials, for improvement of teaching materials and further study of data analysis.

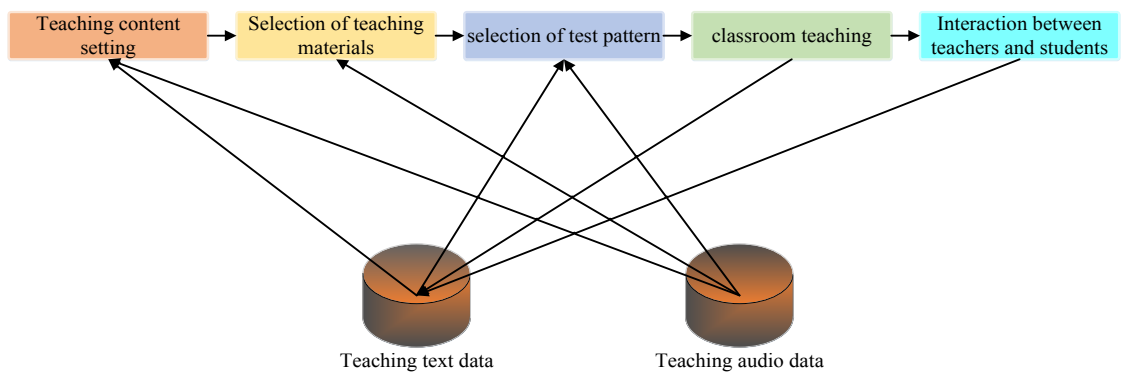

Fig. 3. Framework of the Teacher-controlled Teaching mode 
The corpus-based independent learning mode refers to the training mode constructed based on a student's basic knowledge and corpus suitable for self-adaptive learning by the students. This learning mode changes the situation in which all students who are under different conditions learn the same content and suffer from low learning efficiency. With the assistance of this learning method, different students with different learning needs and personal characteristics would be provided with different learning materials, different training patterns, and post-learning assessment [12]. Students' learning process, evaluation process and results would be recorded and fed back to their corpus, so as to perfect their corpus and learning record database and contribute to corpus building and further learning. As can be seen from Figure 4, the framework of the student-controlled independent learning mode consists of five steps and involves three databases. The specific process is as follows:

1. Analysis of students' present learning situation. Learning data of a student could be extracted from his learning record database and corpus database and analyzed to identify the student's learning level, learning needs, ability characteristics and other information.

2. Selection of the learning material. The learning material suitable for the students is selected from the database of learning materials according to the student's various characteristics identified in step 1 ;

3. Design of the student training mode. Learning tasks are designed based on the student's learning characteristics, the learning content and the learning materials provided in step 2;

4. Student's independent learning process. The student should learn and complete the learning tasks set in step 3. In the process of finishing these learning tasks, a variety of outputs from the student, such as answering practice questions and other questions, etc., will be feedback to the student's learning record and corpus;

5. Learning assessment and feedback. After the learning tasks are completed, the learning situation for the current learning task will be evaluated and the evaluation result will be fed back to the student's learning record database.

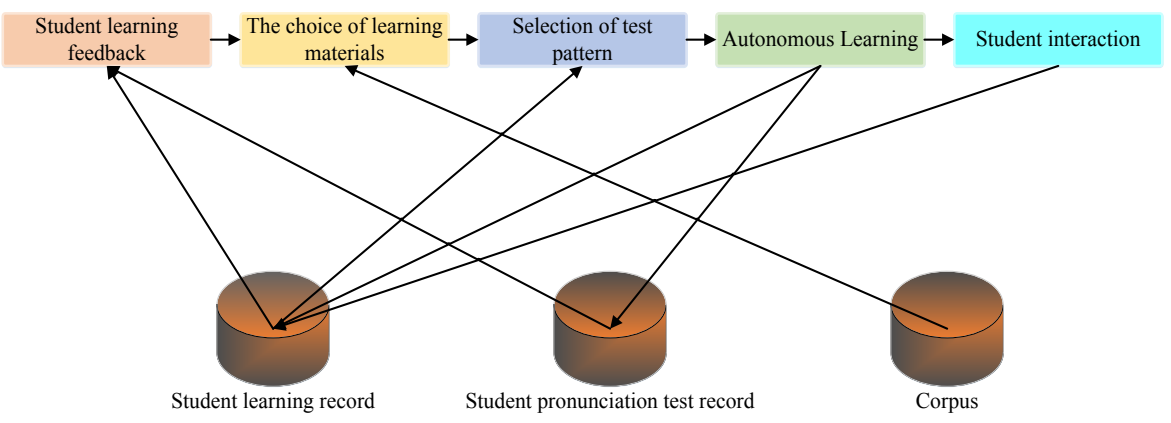

Fig. 4. Framework of the Student-controlled Independent Learning Mode 


\subsection{Interface display of the multimedia-based English pronunciation learning system}

The login interface of self-adaptive learning in the multimedia-based English pronunciation system is shown in Figure 2-5. Teachers choose the teaching mode, while students choose the independent learning mode. They respectively use their faculty number and student number to log. Different accounts enjoy different permissions.

Figure 6 shows the initial interface of the teaching mode. The main modules of the current teaching mode are learning progress query, class schedule query, student achievement query, teaching evaluation query, student list query, courseware query, etc. This design is the first version and will be added with more required modules when necessary. After clicking the setting button, the use can start to set the teaching content, etc. The system interacts with each database in the backstage and is transparent to the user. After finishing setting, the user can click to start teaching. The teaching content will be automatically displayed on students' computer through the multimedia English pronunciation system. During the learning process, the teacher and students can interact with each other via the corresponding button on the console. The teaching process will be automatically stored in the corresponding teaching corpus and teaching material corpus. Similarly, students' answers would be automatically passed to the corresponding student corpus.

Figure 5 and 6 illustrates the production of courseware in the student-controlled independent learning mode. After login, students can check their own learning situation, primarily including the following modules: self-learning evaluation module, my grades, my schedule, learning progress query, exercise books, Bookstore and my error set. Like the teaching mode, the independent learning mode can be added with more required modules later. The setting button is for setting independent learning. In the backstage, learning tasks of the corresponding learning difficulty will be set according to the student's learning records, corpus and so on. After clicking the Start selflearning button, the user can begin learning. The output of the process would be automatically transferred to the appropriate database.

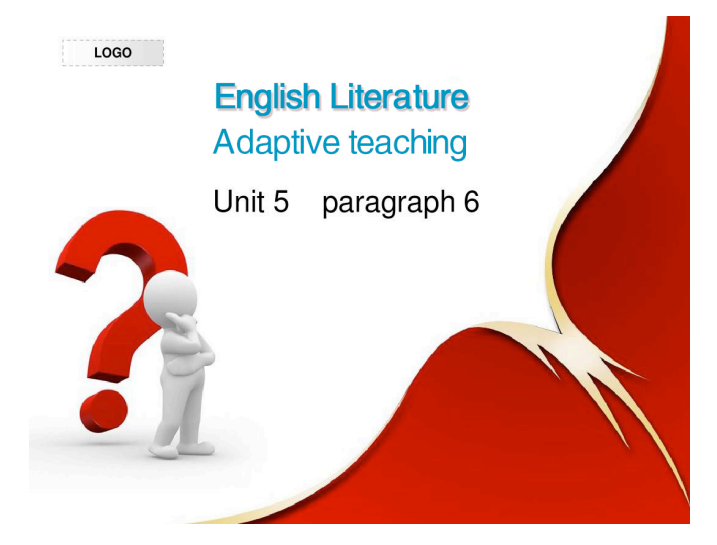

Fig. 5. Display of Courseware Content of the Self-adaptive Learning System 


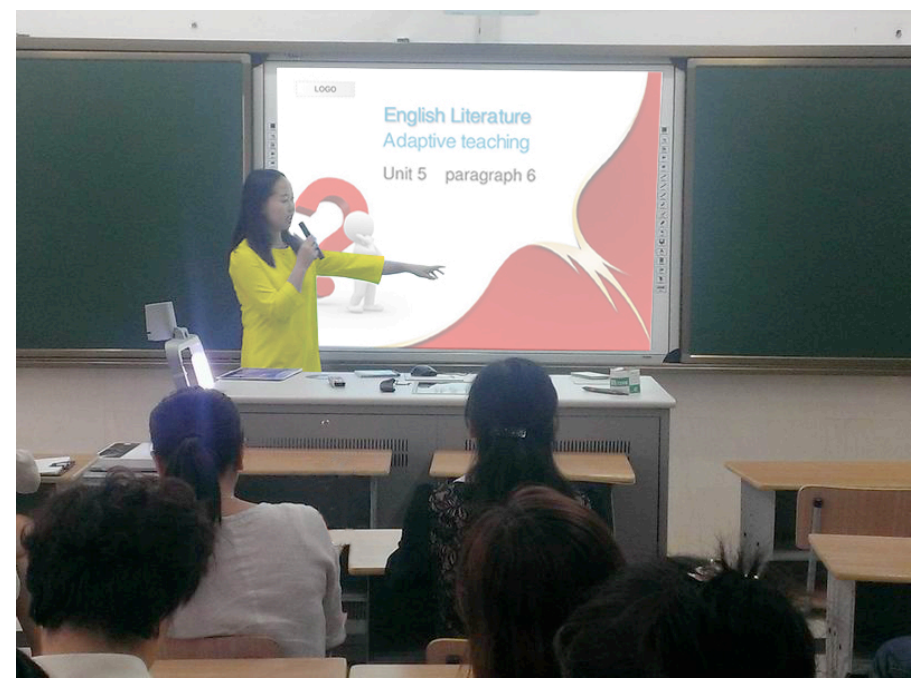

Fig. 6. Display of Scene of the Self-adaptive Learning System

\section{$3 \quad$ Analysis and Discussion}

A randomized controlled trial is recognized as the gold standard for evaluation of interventions which can be avoided to the greatest extent possible bias in the design and implementation of clinical test, balance confounding factors, improve the effectiveness of statistical tests and many other advantages. In order to test the effectiveness of this learning system, we conducted a comparative experiment by selecting the exquisite course of "English Literature" for students of Grade 2015 majoring in English at Hebei North University for contrast. Statistically, the proportion of English major in Chinese universities is as high as 90 percent. However, the concentrated English training mostly fails to realize characterized teaching or to cultivate graduates who are not in line with the needs of the market. Notably, most graduates majoring in English face great difficulty in employment. In this sense, how to improve the employment rate of students is currently an important direction for English teaching reform. Selfadaptive learning system is featured by the ability to guide students to engage in positive thinking, operation and active access to knowledge and skills in the process of observing practical cases and solving problems, and to indirectly improve the employability of students.

In this study, 100 students of Grade 2015 and 100 counterparts of Grade 2014 were selected for comparison. The comparison results are shown in Table 3-1, where the first group of data is the grades of students of Grade 2015, while the second group is the grades of students of Grade 2014. Before the experiment, those students did not differ in their academic performance, but were taught by the same teacher in the same teaching way. Therefore, they can be involved in the comparative experiment. 
Table 1. Learning Comparison of 100 Students of Grade 2015 and 100 Students of Grade 2014 in "English Literature"

\begin{tabular}{|c|c|c|c|c|c|c|}
\hline \multicolumn{2}{|c|}{ Item } & Excellent & Good & General & Relatively poor & Quite poor \\
\hline \multicolumn{2}{|l|}{ Speaking } & $9 / 5$ & $71 / 45$ & $15 / 40$ & $4 / 7$ & $1 / 3$ \\
\hline \multicolumn{2}{|l|}{ Translation } & $21 / 13$ & $65 / 37$ & $9 / 40$ & $5 / 6$ & $0 / 4$ \\
\hline \multicolumn{2}{|l|}{ Reading } & $19 / 10$ & $67 / 40$ & $8 / 35$ & $6 / 11$ & $0 / 4$ \\
\hline \multicolumn{2}{|l|}{ listening } & $10 / 5$ & $69 / 40$ & $16 / 45$ & $3 / 6$ & $2 / 4$ \\
\hline \multirow{3}{*}{ Question type } & Single choice & $37 / 21$ & $50 / 49$ & $13 / 27$ & $0 / 3$ & $0 / 4$ \\
\hline & Cloze & $30 / 20$ & $51 / 39$ & $15 / 31$ & $4 / 9$ & $0 / 1$ \\
\hline & Writing & $11 / 7$ & $60 / 43$ & $13 / 35$ & $10 / 7$ & $6 / 8$ \\
\hline
\end{tabular}

Table 2. 2014 and grade 2015 good and excellent results variance analysis

\begin{tabular}{lcccccc}
\hline \multicolumn{1}{c}{ Group } & Observations & Sum & Average & Variance & & \\
\hline 2015 & 7 & 570 & 81.42857 & 31.61905 & & \\
2014 & 7 & 374 & 53.42857 & 70.61905 & & \\
Variance & & & & & & \\
Differences & SS & df & MS & F & P-value & F crit \\
Between groups & 2744 & 1 & 2744 & 53.67862 & $9.14 \mathrm{E}-06$ & 4.747225 \\
Intra-group & 613.4286 & 12 & 51.11905 & & & \\
Total & 3357.429 & 13 & & & & \\
\hline
\end{tabular}

Table 3. Analysis of variance of 2014 grades and 2015 grades in the five groups

\begin{tabular}{lccccc}
\hline \multicolumn{1}{c}{ Group } & Observations & Sum & Average & Variance & \\
\hline 2015 Excellent & 7 & 137 & 19.57143 & 115.2857 & \\
2014 Excellent & 7 & 81 & 11.57143 & 45.28571 & \\
2015 Good & 7 & 433 & 61.85714 & 72.14286 & \\
2014 Good & 7 & 293 & 41.85714 & 16.80952 & \\
2015 Commonly & 7 & 89 & 12.71429 & 9.571429 & \\
2014 Commonly & 7 & 253 & 36.14286 & 36.80952 & \\
2015 Relatively poor & 7 & 32 & 4.571429 & 9.285714 & \\
2014 Relatively poor & 7 & 49 & 7 & 6.333333 & \\
2015 Poor & 7 & 9 & 1.285714 & 4.904762 & \\
2014 Poor & 7 & 28 & 4 & 4.333333 & \\
Variance & & & & & P-value \\
Differences & SS & df & MS & F rit \\
Between groups & 25395.2 & 9 & 2821.689 & 87.96833 & 3.48E-31 \\
Intra-group & 1924.571 & 60 & 32.07619 & & \\
Total & 27319.77 & 69 & & & \\
\hline
\end{tabular}


It be seen from Table 1 that students' ability of listening, speaking, reading and writing, especially in the aspect of translation, reading, single choice, cloze and writing, were improved significantly after employing the self-adaptive learning mode of the multimedia-based English pronunciation learning system. In addition, the most remarkable improvement could be found in their translation and reading, which might be closely related to the maturity and perfection of their translation and reading corpus. At the same time, it can be noticed that students were obviously deficient in speaking, listening and writing, which is related to the traditional English teaching mode.

We also did a questionnaire survey targeting at the English students of Grade 2015 in the comparative experiment. As shown in the survey, $93.7 \%$ of the students thought that their learning ability has been improved and extended their average daily learning time by 30 minutes. We analyze the good and excellent results of grade 2014 and grade 2015. (See table 2 and table 3)

As can be seen from the summary in Table 2, the good rate of the grades of students in Grade 2015 who adopted the multimedia-based English pronunciation learning system was about $81 \%$ on average, and the good rate of writing which accounted for the lowest proportion was $71 \%$, while the good rate of the grades of students in Grade 2014 was only about $53 \%$, and the good rate of multiple choice which accounted for the highest proportion was only 70\%. The variance in Grade 2015 is significantly lower than that in Grade 2014, from which it can see that the multimedia-based English pronunciation learning system has a significant impact on the improvement of grades. In addition, $\mathrm{P}<0.05$ can be seen from both variance between groups and variance within groups, indicating that the multimedia-based English pronunciation learning system has a very significant impact on the grades. Seen from 5 groups of grades, the significant factor for the impact of the multimedia-based English learning system on the grades is $3.48 \mathrm{E}-31$, indicating a very significant overall impact.

\section{Conclusion}

From the analysis above, we can see that the system has the following advantages. The first one is rich teaching resources: in practical applications, a wealth of teaching resources can not only provide necessary language learning materials to learners but also offer multi-functional teaching resource retrieval for teachers, to meet various needs of teachers in the teaching process, such as: seeking an article or preparing questions and so on. The second advantage is the individualization of teaching process: the corpus-based adaptive learning mode achieves personalized language learning through the construction of corpus. It can make the difficulty of teaching materials adapt to the language level of the learner and the content of teaching materials meet the student's learning needs. More importantly, the learning system is compatible with analog language lab teaching, so that it can further enhance students' language learning results and interests.

The self-adaptive learning model of the multimedia-based English pronunciation system has a positive meaning to improvement of teaching efficiency, change from 
the teacher-driven teaching mode and students' independent learning mode to the student-controlled independent mode, and transformation from "spoon-feeding" pattern to students' self-induction. Therefore, it can indirectly improve students' self-learning ability and increate the employment rate of English graduates, enjoying a high research value and broad application prospect for the reform of English teaching. Nonetheless, the construction of corpus related to English learning is not perfect. Besides, it is still necessary to constantly explore and discover many research directions of the multimedia teaching self-adaptive mode.

\section{$5 \quad$ References}

1. Robbins, R.N., Mellins, C.A., Leu, C.S., Rowe, J., Warne, P., Abrams, E.J., Witte, S., Stein, D.J., \& Remien, R.H. "Enhancing lay counselor capacity to improve patient outcomes with multimedia technology," AIDS and Behavior, vol. 19, no. 2, pp. 163-176, June 2015. https://doi.org/10.1007/s10461-014-0988-4

2. Parshina, L. "Multimedia technologies as a tool for teaching supervision over the students' skills (within the course on "music theory training")," Life Science Journal, vol. 11, no. 6, pp. 547-551, June 2014.

3. Tsou, W., Wang, W., \& Tzeng, Y. "Applying a multimedia storytelling website in foreign language learning," Computers \& Education, vol. 47, no. 1, pp. 17-28, August 2006. https://doi.org/10.1016/j.compedu.2004.08.013

4. Fan, Y.F. "Strengths and weaknesses of multimedia in Chinese language teaching," China Information Technology Education, no. 6, pp. 161-161, March 2014.

5. Xu, B., Zhuang, Y., Xue, Y., \& Wang, Z. "Self-adaptive learning based immune algorithm," Journal of Central South University, vol. 19, no. 4, pp. 1021-1031, April 2012. https://doi.org/10.1007/s11771-012-1105-3

6. Babaee, R., \& Yahya, W.R.B.W. "Significance of literature in foreign language teaching," International Education Studies, vol. 7, no. 4, pp. 80-85, April 2014. https://doi.org/10.5539/ies.v7n4p80

7. Tian, L., Du, X.B. "Discussion on APP-based mobile multimedia networked foreign language teaching," Course Education Research, no. 20, 99-100, August 2015.

8. Su, Y.N., Huang, Y.L. "Design and application of flipped classroom based on interactive experiment simulation software - take virtual multimedia teaching system as an example," China Educational Technology, no. 10, pp. 60-67, October 2015.

9. Liu, X., \& Zheng, P.Y. "Multi-media teaching research and countermeasures," Education and Vocation, no. 14), pp. 164-165, May 2014.

10. Gulzar, Z. "Educational System of J\&K in the light of Evolutionary Multimedia Technology: A Case Study," International Journal, vol. 2, no. 4, pp. 66-75, April 2014.

11. Unold, O. "Self-adaptive learning classifier system," Journal of Circuits, Systems, and Computers, vol. 19, no. 1, pp. 275-296, February 2010. https://doi.org/10.1142/S0218 126610006256

12. Niknam, T., Azizipanah-Abarghooee, R., Zare, M., \& Bahmani-Firouzi, B. "Reserve constrained dynamic environmental/economic dispatch: A new multiobjective self-adaptive learning bat algorithm," IEEE Systems Journal, vol. 7, no. 4, pp. 763-776, December 2013. https://doi.org/10.1109/JSYST.2012.2225732 


\section{Authors}

Jie Mei is a Docent of Hebei North University, Zhangjiakou, China. Her research interests include English Literature and Multimedia teaching system. (meijiehbnu@163.com)

Yanhong Guo is a Docent of Hebei North University, Zhangjiakou, China. Her research interests include English Literature and Multimedia teaching system. (meijiehbnu@163.com)

Xiaokun Li is a Docent of Hebei North University, Zhangjiakou, China. Her research interests include Business English. (meijiehbnu@163.com)

Submitted 03 December 2016. Published as resubmitted by the authors 12 January 2017. 